\title{
ЭКОНОМИКА ПРЕДПРИНИМАТЕЛЬСТВА В ВЫСШЕМ УЧЕБНОМ ЗАВЕДЕНИИ: ОСОБЕННОСТИ РОССИЙСКОГО ПОДХОДА
}

\author{
(C) 2018 Строганов Игорь Алексеевич \\ кандидат экономических наук, доцент \\ кафедра предпринимательства и логистики \\ Российский экономический университет имени Г.В. Плеханова \\ 115093, г. Москва, Стремянный пер., 36 \\ E-mail: stroganov.ia@rea.ru \\ (c) 2018 Забазнова Наталья Михайловна \\ старший преподаватель \\ кафедра иностранных языков № 3 \\ Российский экономический университет им. Г.В. Плеханова \\ 115093, г. Москва, Стремянный пер., 36 \\ E-mail:nmzabaznova@gmail.com \\ (c) 2018 Мурадова Ирина Юрьевна \\ старший преподаватель \\ кафедра иностранных языков № 3 \\ Российский экономический университет им. Г.В. Плеханова \\ 115093, г. Москва, Стремянный пер., 36 \\ E-mail:gryad@mail.ru
}

В статье авторов рассматриваются актуальные для Российской Федерации особенности организации предпринимательской деятельности в высшем учебном заведении в экономическом аспекте. Объектом исследования статьи является предпринимательская деятельности в высшем учебном заведении Российской Федерации, а предметом - экономическая составляющая данного процесса. Теоретико-методологическое значение исследования заключается в расширенном представлении направлений предпринимательской деятельности во взаимосвязи с их доходными базами, систематизированными во времени, а практическое - в выявлении специфики организации предпринимательской инициативы в высших учебных заведениях Российской Федерации.

Ключевые слова: экономика, предпринимательство, высшее учебное заведение, особенности, эффективность, проблемы.

Процесс инвестирования в образовательный сектор был всегда сопряжен с рядом проблем, связанных, в первую очередь, с возникновением и содержанием эффекта в экономической плоскости [3, с.29]. Так, согласно данным неофициальной статистики до 2007 года более 95\% высших учебных заведений в Российской Федерации практически не инициировали предпринимательскую деятельность безотносительно образовательного профиля.

С переходом на новый путь развития в сфере высшего профессионального образования, в значительной мере ориентированный на применение инноваций [1, с.131], существенную значимость стали приобретать альтернативные статьи дохода [4, с.735], связанные, в том числе с осуществлением коммерческих исследований для хозяйствующих субъектов [6]. В связи с этим доля альтернативных предпринимательских доходов [5, с.311] высших учебных заведений Российской Федерации, отличных от образовательной деятельности, за последние десять лет выросла более чем в 11,21 раза (рисунок 1).

Актуальными на начало 2018 года направлениями предпринимательской деятельности [2, с.33], осуществляемыми высшими учебными заведениями Российской Федерации стали:

- заключение договоров с хозяйствующими субъектами на проведение научно-исследовательских работ. Источником дохода в рамках данного направления являются выплаты по результатам проведенных исследований, оформленных в письменном виде в форме отчетов. Для более чем $75 \%$ проанализированных объек- 


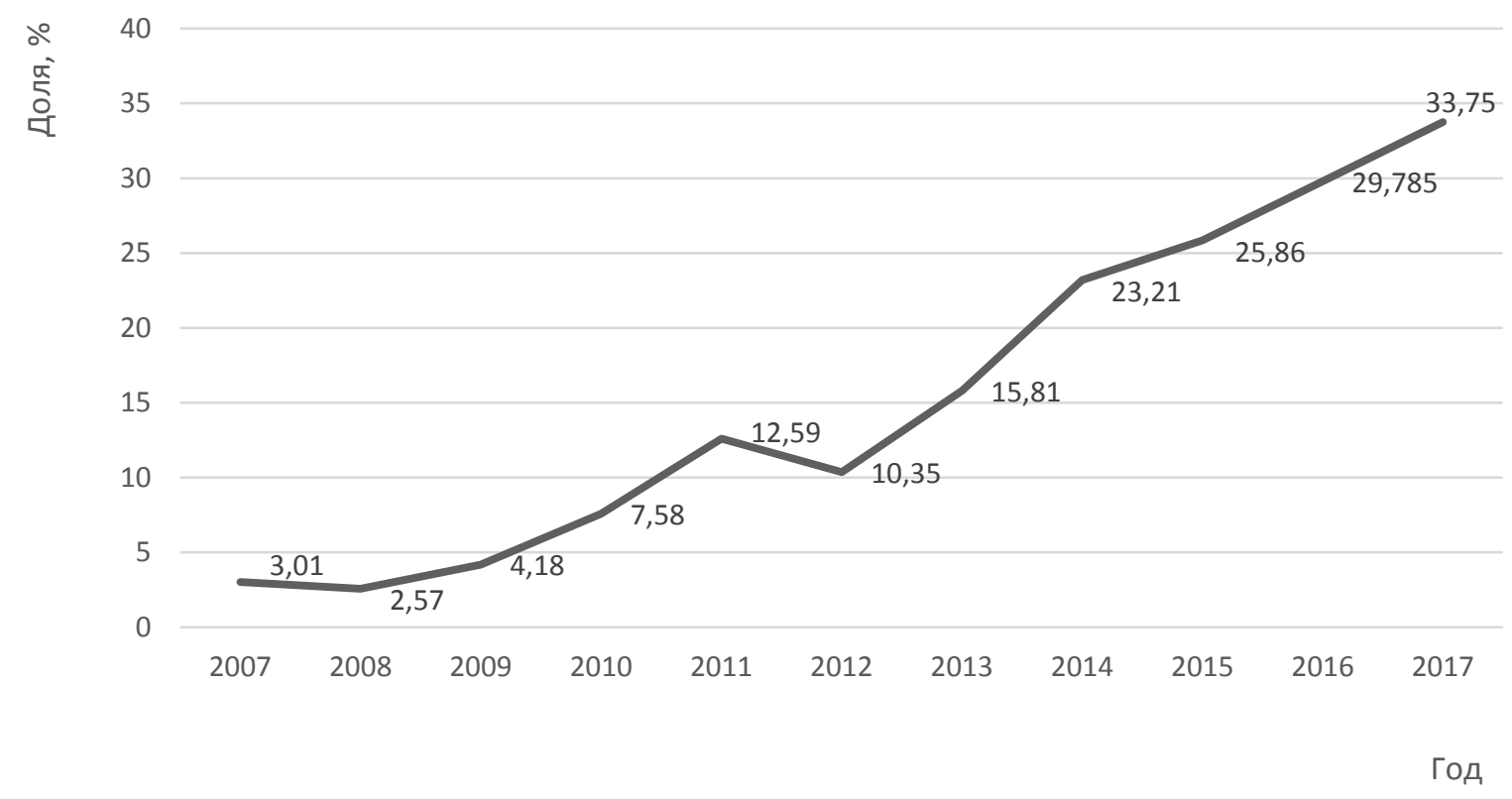

Puc. 1. Динамика доли альтернативных предпринимательских доходов высших учебных заведений Российской Федерации, отличных от образовательной деятельности, за 2007-2017 годы

тов данное направление предпринимательской деятельности носит, к сожалению, не систематический характер;

- формирование малых инновационных предприятий с целью получения учредительного дохода. Доход по обозначенному направлению формируется из чистой прибыли организованных с участием высшего учебного заведения предприятий и более чем в 50\% случаев носит систематический характер;

- коммерциализация нематериальных активов, отделимых от индивидуума (патенты, промышленные образцы, полезные модели и прочее). Получение дохода здесь, формируемого за счет отчислений правообладателям прав на нематериальные активы, практически у 97\% исследуемых объектов носит систематический характер;

- развитие дополнительных образовательных программ (курсы повышения квалификации, программы переподготовки кадров и прочее). Генерируемые доходы по данному направлению, возникающие из оплаты заключенных договоров со слушателями, в 90\% случаев носят систематический характер;

- участие в программах грантов федеральной и региональной направленности. Доходная часть в рамках указанного направления формируется из выплат участникам (победителям) грантов. Систематичность получения дохода здесь достигает значимой регулярности в сред- нем у порядка 47\% объектов;

- прочие направления предпринимательской деятельности. Источником доходов здесь в основном являются выплаты по договорам частных консультаций и носят преимущественно единичный характер.

Распределение доходов, полученных высшими учебными заведениями Российской Федерации в рамках обозначенной совокупности направлений предпринимательской деятельности по итогам 2017 года приведено в табл. 1. Из данной таблицы можно увидеть, что основную долю доходов высших учебных заведений от предпринимательской деятельности, исключая базовую образовательную деятельность, формируют договора на проведение научно-исследовательских работ, доля которых по итогам 2017 года составила 31,81\%.

Следующими по значимости направлениями предпринимательской деятельности являлись: участие в программах грантов федеральной и региональной направленности (доля дохода порядка 23,85\%) и развитие дополнительных образовательных программ (доля равняется 21,97\%).

Менее значимыми направлениями предпринимательской деятельности высших учебных заведений Российской Федерации были: формирование малых инновационных предприятий с целью получения учредительного дохода и коммерциализация нематериальных активов, отделимых от индивидуума. Суммарная доля 
Таблица 1. Распределение доходов, полученных высшими учебными заведениями Российской Федерации в рамках обозначенной совокупности направлений предпринимательской деятельности по итогам 2017 года в \%\%

\begin{tabular}{|l|c|}
\hline \multicolumn{1}{|c|}{ Направление предпринимательской деятельности } & \multicolumn{1}{|c|}{$\begin{array}{c}\text { Доля дохода } \\
\text { по направлению }\end{array}$} \\
\hline $\begin{array}{l}\text { Заключение договоров с хозяйствующими субъектами на проведение } \\
\text { научно-исследовательских работ }\end{array}$ & 31,81 \\
\hline Участие в программах грантов федеральной и региональной направленности & 23,85 \\
\hline Развитие дополнительных образовательных программ & 21,97 \\
\hline $\begin{array}{l}\text { Формирование малых инновационных предприятий с целью получения } \\
\text { уредительного дохода }\end{array}$ & 12,30 \\
\hline Коммерциализация нематериальных активов, отделимых от индивидуума & 7,55 \\
\hline Прочие направления предпринимательской деятельности & 2,52 \\
\hline Итого & 100,00 \\
\hline
\end{tabular}

по двум направлениям дохода здесь составила $19,85 \%$.

На прочие направления предпринимательской деятельности высших учебных заведений Российской Федерации, без учета базовой образовательной деятельности, приходилось не более 2,6\% доходов.

Специфика рынка Российской Федерации определила ряд отличительных особенностей функционирующих в нем высших учебных заведений, организующих предпринимательские инициативы:

- относительно высокий уровень рентабельности инвестиций (ROI) в анализируемые предпринимательские проекты по сравнению с развитыми странами (рисунок 2). Данные ри- сунка свидетельствуют о том, что среднее значение ROI для высших учебных заведений Российской Федерации за анализируемый период равняется чуть менее 24\%, против 15,6\% и 13,3\% для таких развитых стран, как Германия и США соответственно. Основная причина сложившейся ситуации - низкий, в сравнении с развитыми странами, фонд оплаты труда сотрудников высших учебных заведений;

- краткосрочный характер сроков заключения договоров по предпринимательским проектам высших учебных заведений (рисунок 3). Из рисунка можно увидеть, что средний срок заключения договоров для высших учебных заведений в Российской Федерации составил менее 1 года в то время, как для таких стран как Япония

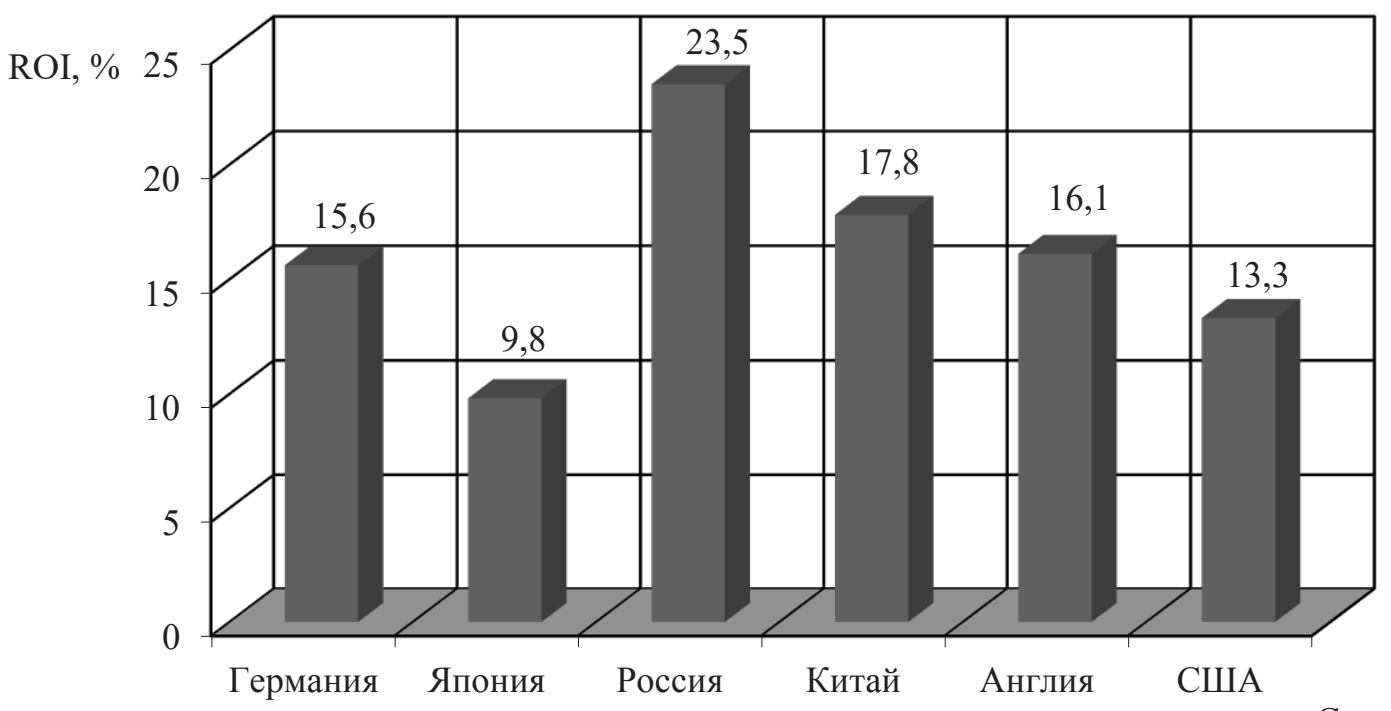

Страна

Puc. 2. Уровень рентабельности инвестиций (ROI) в анализируемые предпринимательские проекты высших учебных заведений в различных странах в 2017 году (усредненные данные) [6] 


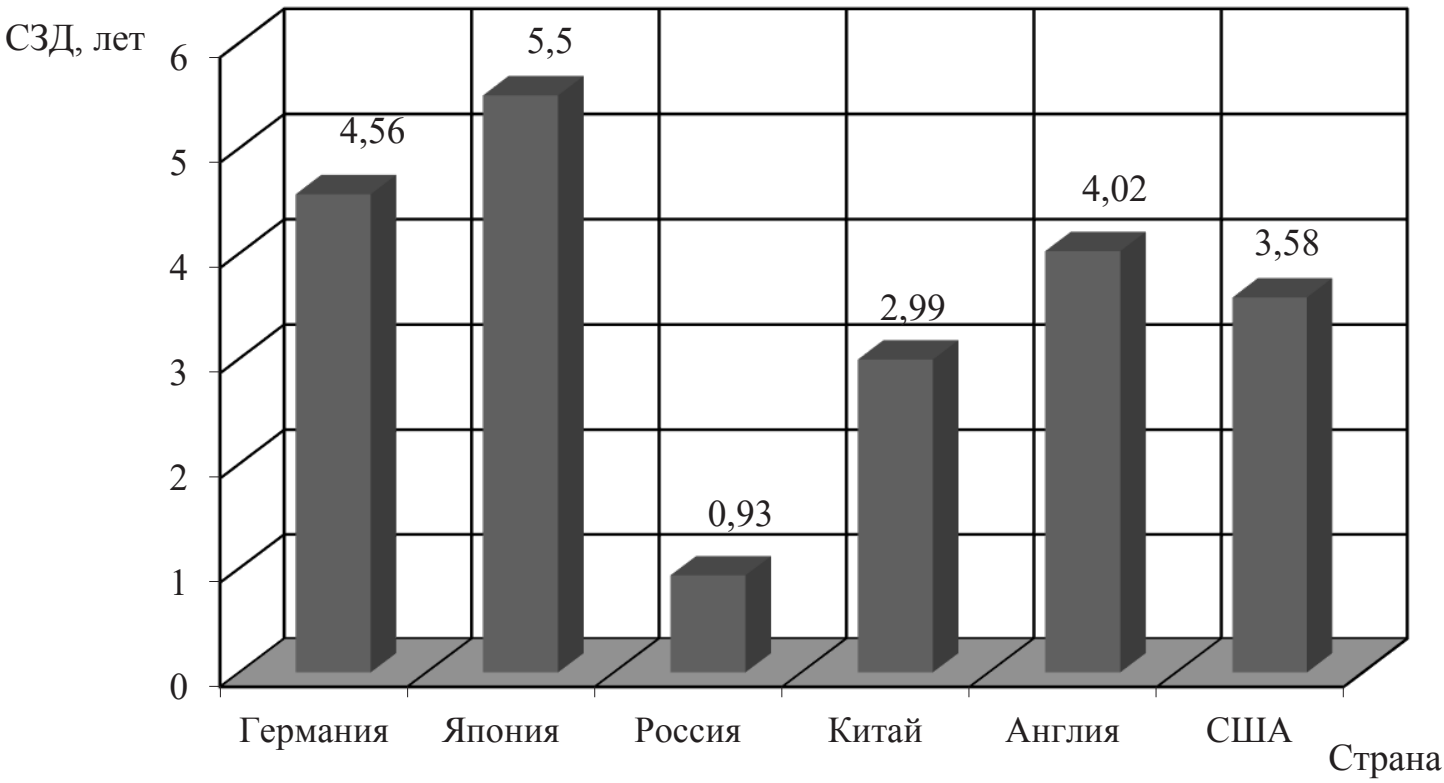

Puc. 3. Средний срок заключения договоров (СЗД) по анализируемым предпринимательским проектам высших учебных заведений в различных странах в 2017 году

Таблица 2. Перспективы развития рынка предпринимательства в высших учебных заведениях различных стран на 2019-2023 годы

\begin{tabular}{|c|c|c|}
\hline Страна & Перспективы развития,\% & Ошибка прогноза,\% \\
\hline Германия & 256,38 & 1,23 \\
\hline Япония & 191,15 & 2,15 \\
\hline Россия & 359,86 & 0,89 \\
\hline Китай & 278,37 & 3,75 \\
\hline Англия & 119,71 & 0,61 \\
\hline США & 131,19 & 1,53 \\
\hline
\end{tabular}

и Англия он составляет 5,5 и 4,02 года соответственно. Одной из значимых причин создавшегося положения является низкая доля договоров со стратегическими клиентами на федеральном уровне;

- значительный потенциал развития рынка предпринимательских услуг в высших учебных Российской Федерации на ближайшие 5 лет (таблица 2).

По предварительным оценкам специалистов консалтинговой компании Ernst\&Young перспективы развития рынка предпринимательства в высших учебных заведениях Российской Федерации на 2019-2023 годы составляют $359,86 \%$ против 131,19\% для США и 119,71\% для Англии. Вероятной причиной обозначенной особенности является низкая вовлеченность высших учебных заведений Российской Федерации в процесс интеграции рынка коммерческих услуг профессионального характера.
По итогам можно отметить, что предпринимательская деятельность в высших учебных заведениях Российской Федерации формализуется в рамках ряда направлений от заключения договоров с хозяйствующими субъектами на проведение научно-исследовательских работ до участия в программах и грантах федеральной и региональной направленности.

Особенности российского подхода к организации предпринимательской деятельности в высших учебных заведениях относительно развитых стран проявляются: в относительно высоком уровне рентабельности инвестиций (ROI) в анализируемые предпринимательские проекты; краткосрочном характере сроков заключения договоров по предпринимательским проектам высших учебных заведений; значительном потенциале развития рынка предпринимательских услуг на ближайшие 5 лет. 


\section{Библиографический список}

1. Журавлева Ю.А. Высшее образование россиян как фактор готовности к инновационным преобразованиям: региональный аспект / Ю.А. Журавлева // Экономические науки. Москва. 2013. № 11. С.129-133.

2. Коновалова М.Е. Предпринимательство в системе факторов производства / М.Е. Коновалова и другие // Экономические науки. Москва. 2017. № 4. С.33-36.

3. Canterbury R.M. Higher education marketing: a challenge // Journal of College Admission. 1999.165 (3) P. $22-30$.

4. Fallon D. (2012). Europe inches forward on Higher education reform, focus: Germany. Social Research, 79(3), pp. 713-740.

5. Kirby, D.A., Guerrero, M., \& Urbano, D. Making universities more entrepreneurial: Development of a model // Canadian Journal of Administrative Sciences, Revue Canadienne des Sciences de l’Administration. 2011. 28(3). P. 302-316.

6. Компания Ernst\&Young [Электронный ресурс]: аналитические материалы - Официальный сайт компании Ernst\&Young, 2018. - Режим доступа: http:// www.ey.com/

Received for publication on 01.09.2018 